\title{
A LYAPUNOV-TYPE INEQUALITY FOR A FRACTIONAL BOUNDARY VALUE PROBLEM WITH CAPUTO-FABRIZIO DERIVATIVE
}

\author{
Mokhtar Kirane And Berikbol T. TorebeK
}

Abstract. In this work we obtain a Lyapunov-type inequality for a fractional differential equation with Caputo-Fabrizio operator subject to Dirichlet-type boundary conditions. As an application, we obtain a lower bound for the eigenvalues of corresponding equations.

Mathematics subject classification (2010): 35A09, 34K06.

Keywords and phrases: Lyapunov inequality, Caputo-Fabrizio derivative, Green function.

\section{REFERENCES}

[1] A. Tiryaki, Recent developments of Lyapunov-type inequalities, Adv. Dyn. Syst. Appl. Vol. 5, No. 2, 231-248 (2010).

[2] M. Hashizume, Minimization problem related to a Lyapunov inequality, J. Math. Anal. Appl. Vol. 432, No. 1, 517-530 (2015).

[3] T. SUN AND J. LiU, Lyapunov inequality for dynamic equation with order $n+1$ on time scales, J. Dyn. Syst. Geom. Theor. Vol. 13, No. 1, 95-101 (2015).

[4] A. M. Liapounoff, Probleme général de la stabilité du mouvement, Ann. Fac. Sci. Univ. Toulouse, Vol. 9, 203-474 (1907).

[5] R. A. C. FERreira, A Lyapunov-type inequality for a fractional boundary value problem, Fract. Calc. Appl. Anal. Vol. 16, No. 4, 978-984 (2013).

[6] Q. MA, CH. MA AND J. WANG, A Lyapunov-type inequality for a fractional differential equation with Hadamard derivative, Journal of Mathematical Inequalities, Vol. 11, No. 1, 135-141 (2017).

[7] R. A. C. FERREIRA, On a Lyapunov-type inequality and the zeros of a certain Mittag-Leffler function, J. Math. Anal. Appl. Vol. 412 No. 2, 1058-1063 (2014).

[8] M. JLELI AND B. SAMET, Lyapunov-type inequalities for a fractional differential equation with mixed boundary conditions, Math. Inequal. Appl. Vol. 18, No. 2, $443-451$ (2015).

[9] D. O'REGAN AND B. SAMET, Lyapunov-type inequalities for a class of fractional differential equations, J. Inequal. Appl. Vol. 2015, No. 247, 1-10 (2015).

[10] J. Rong, C. Z. BAI, Lyapunov-type inequality for a fractional differential equations with fractional boundary value problems, Adv. Difference. Equ. Vol. 2015, No. 82, 1-10 (2015).

[11] S. Eshaghi, A. Ansari, Lyapunov inequality for fractionaldifferential equations with Prabhakar derivative, Math. Inequal. Appl. Vol. 19, No. 1, 349-358 (2016).

[12] R. A. C. FERreirA, Lyapunov-Type Inequalities for some Sequential Fractional Boundary Value Problems, Advances in Dynamical Systems and Applications, Vol. 11, No. 1, 33-43 (2016).

[13] A. Chidouh, D. F. M. Torres, A generalized Lyapunov's inequality for a fractional boundary value problem, Journal of Computational and Applied Mathematics, Vol. 312, No. 1, 192-197 (2017).

[14] M. Caputo and M. Fabrizio, A New Definition of Fractional Derivative without Singular Kernel, Progr. Fract. Differ. Appl. Vol. 1, No. 2, 1-13 (2015).

[15] J. Los ada And J. J. Nieto, Properties of a New Fractional Derivative without Singular Kernel, Progr. Fract. Differ. Appl. Vol. 1, No. 2, 87-92 (2015). 